\section{Análise Crítica da Utilidade do Teste de \\ Clonidina - Hormônio de Crescimento (GH) no Diagnóstico do Homem Infértil}

\section{RESUMO}

O presente trabalho visa analisar a confiabilidade do teste de clonidina - GH (TC-GH) no diagnóstico de uma insuficiência relativa de $\mathrm{GH}$ em uma população de homens inférteis. Vinte e sete pacientes foram classificados em 3 grupos de acordo com a dose de clonidina. Os grupos I (clonidina $0,150 \mathrm{mg}$ ) e II (clonidina $0,200 \mathrm{mg}$ ) tinham 9 e 6 pacientes oligozoospérmicos, respectivamente. O grupo III (clonidina $0,400 \mathrm{mg}$ ) tinha 5 pacientes oligozoospérmicos (subgrupo Illa) e 7 normozoospérmicos (subgrupo Illb). Trinta e um TC-GH foram realizados e vinte e nove deles foram analisados; cinco $(17,2 \%)$ resultaram normais (1 no grupo I, 1 no grupo III e 3 no grupo llib). As respostas do $\mathrm{GH}$ após 60.90 e 120 minutos do estímulo não mostraram diferença significativa nos grupos I, II e III nem entre os subgrupos IIla e IIIb. Conclui-se que o TC-GH não é de utilidade no diagnóstico de uma relativa insuficiência de GH no homem infértil, independente da dose de clonidina. A razão é a incapacidade da clonidina produzir um estímulo de $\mathrm{GH}$ confiável no homem adulto. (Arq Bras Endocrinol Metab 1999;43/5: 373 -376).

Unitermos: Hormônio de crescimento; Teste clonidina - GH; Infertilidade masculina; Insuficiência de GH

\begin{abstract}
The aim of this study was to analyse the reliability of the $\mathrm{GH}$ - clonidine test ( $\mathrm{GH}-\mathrm{CT}$ ) in the diagnosis of a relative $\mathrm{GH}$ insufficiency in an infertile male population. Twenty seven pacients were classified in 3 groups according to clonidine dosage. Groups I (clonidine $0.150 \mathrm{mg}$ ) and II (clonidine $0.200 \mathrm{mg}$ ) had 9 and 6 oligozoospermic patients, respectively. Group III (clonidine $0.400 \mathrm{mg}$ ) had 5 oligozoospermic (subgroup IIIa) and 7 normozoospermic patients (subgroup lilb). Thirty one GH-CT were performed and 29 of them were included in the study. Five (17.2\%) normal GH-CT were observed (1 in group 1,1 in group II and 3 in subgroup IIlb). GH responses at 60,90 and 120 min after clonidine stimulation showed no significant differences in groups I, II and III, neither between subgroups IIla and Illib. We conclude that the $\mathrm{GH}-\mathrm{CT}$ is of no use in the diagnosis of a relative $\mathrm{GH}$ insufficiency in the infertile male, irrespective of the clonidine dosage. The reason is the clonidine inability to carry out a reliable $\mathrm{GH}$ stimulation in the adult male. (Arq Bras Endocrinol Metab 1999;43/5: 373 -376)
\end{abstract}

Keywords: Growth hormone; $\mathrm{GH}$ - clonidine test; Male infertility; $\mathrm{GH}$ insufficiency

E XISTEM EVIDÊNCIAS DE QUE O GH e o IGF- 1 têm papel importante no sistema reprodutor de ambos os sexos $(1,2)$. Essas evidências são melhor comprovadas na mulher, na qual o GH aumenta a produçăo de estradiol e de progesterona e, também, a divisão celular in vitro das células da granulosa (3). No homem, o GH e o IGF-l teriam um efeito facilitador do processo de síntese de testosterona e de espermatogênese $(2,4)$. No entanto, estudos sobre a fisiopatologia do GH e do IGF-1 no homem perspectiva

\author{
Antônio Carlos Bonaccorsi \\ Denise Boechat Leite \\ Raul Faria Junior
}

Instituto Estadual de Diabetes e
Endocrinologia do Rio de Janeiro-
IEDE, Rio de Janeiro, RJ. 
infértil e, principalmente, sobre a possível ação terapêutica do $\mathrm{GH}$ são pouco conclusivos $(5,6)$. Em 1993, Shimonovitz e cols. (7) encontraram ausência de resposta do $\mathrm{GH}$ ao estímulo pela clonidina $(0,150 \mathrm{mg}) \mathrm{em} 91 \%$ de 11 pacientes azoospérmicos, o que sugeria que a alteração da espermatogênese seria dependente do GH. Diante destes dados, passamos, a partir de 1995, a tentar identificar se em pacientes não azoospérmicos essa ausência de resposta do $\mathrm{GH}$ à clonidina poderia também estar presente. O presente trabalho é uma análise retrospectiva dos exames realizados em pacientes oligozoospérmicos, análise esta que nos levou, a proporção que surgiam os resultados, a ampliar nossa avaliação para também estudar pacientes normozoospérmicos.

\section{MATERIAL E MÉTODOS}

Foram avaliados pelo teste da clonidina - GH, 27 homens inférteis com idades entre 25 e 50 anos (média de 32,6 anos). Ao exame físico todos os pacientes eram bem virilizados e tinham volume testicular total (valor normal acima de $30 \mathrm{ml}$ ) normal, exceto por 2 casos de varicocele e outro que sofrera orquiectomia por criptorquidia. Havia 15 pacientes $(55,5 \%)$ com varicocele. Exceto em 4 pacientes, a infertilidade era primária em todos.

Os testes de clonidina - $\mathrm{GH}$ foram realizados quando havia necessidade da realização de um teste de estímulo com LH-RH (luteinizing hormone-releasing hormone), sendo a facilidade de concomitância dos dois testes o único critério de escọlha dos 27 pacientes. Em 4 pacientes, o teste de clonidina - GH foi repetido na ausência do teste do LR-RH. Portanto, foram realizados ao todo 31 testes. Os testes foram realizados sempre no mesmo local com o paciente em decúbito dorsal e em repouso há pelo menos 15 minutos, sendo sempre acompanhados por um dos autores durante todo o seu desenvolvimento. Nenhum paciente apresentou quadro de hipotensão que causasse preocupação, sendo que todos entraram em sono mais ou menos profundo. $\mathrm{O} \mathrm{GH}$ foi dosado em condições basais e 60, 90 e 120 minutos após a ingestão da clonidina. Foi considerado um teste normal uma resposta do $\mathrm{GH}$ de pelo menos $5 \mathrm{ng} / \mathrm{ml}$.

Os pacientes foram divididos em 3 grupos de acordo com a dose de clonidina utilizada. O grupo I era constituído de 9 pacientes oligozoospérmicos (menos de $20 \times 10^{6}$ espermatozóides $/ \mathrm{ml} \mathrm{e,} \mathrm{de} \mathrm{pelo} \mathrm{menos,} 40 \times 10^{6}$ /ejaculado), os quais receberam $0,150 \mathrm{mg}$ de clonidina. O grupo II $(0,200 \mathrm{mg}$ de clonidina) tinha 6 pacientes oligozoospérmicos e nele foram incluídos mais 4 pacientes não responsivos do grupo I, os quais estavam sendo re-testados com dose mais elevada de clonidina, $o$ que eleva para 10 o número total de testes realizados neste grupo. O grupo III recebeu $0,400 \mathrm{mg}$ de clonidina e era constituído de 5 pacientes oligozoospérmicos (subgrupo IIIa) e 7 pacientes normozoospérmicos (subgrupo IIIb) com diferentes graus de astenospermia, exames estes ainda compatíveis com fertilidade. Estes 7 pacientes tinham $29,4 \times 10^{6}$ a $160 \times 10^{6}$ espermatozóides $/ \mathrm{ml}$ (média de $77,3 \times 10^{6}$ ) e $97 \times 10^{6}$ a $333,6 \times 10^{6}$ espermatozóides/ejaculado (média de 196x106).

As dosagens de $\mathrm{GH}$ foram realizadas utilizandose método imunofluorimétrico com kit da marca Auto Delfia (Wallac / EG \& G). O limite de detecção do $\mathrm{GH}$ por este método é de $0,0 \mathrm{lng} / \mathrm{ml}(0,03 \mathrm{mU} / \mathrm{L})$ e os coeficientes intra e inter-ensaio são de $1,9 \mathrm{ng} / \mathrm{ml}$ $(5,1 \mu \mathrm{mol} / \mathrm{L})$ e $0,9 \mathrm{ng} / \mathrm{ml}(2,5 \mu \mathrm{mol} / \mathrm{L})$, respectivamente. O fator de conversão é: $1 \mathrm{ng} / \mathrm{ml}=2,6 \mu \mathrm{mol} / \mathrm{L}$.

As respostas de $\mathrm{GH}$ após 60,90 e 120 minutos do estímulo pela clonidina foram comparadas entre os grupos I, II e III por análise de variância (ANOVA) e nos subgrupos IIIa e IIIb foi utilizado o teste t pareado (Student).

\section{RESULTADOS}

Dos 31 testes realizados, $\mathrm{l}$ do grupo II e $\mathrm{I}$ do subgrupo IIIb foram excluídos da avaliação por terem valores elevados de $\mathrm{GH}$ basal, o que foi atribuído ao "stress" da prova. Dentre os 29 testes remanescentes, 5 deles $(17,2 \%)$ mostraram resultados normais, sendo 1 $(11,1 \%)$ nos 9 pacientes do grupo $I, 1(11,1 \%)$ nos 9 pacientes do grupo II e $3(17,2 \%)$ nos 11 pacientes do grupo III. Estes 3 testes normais foram encontrados no subgrupo IIIb, ou seja, em $50 \%$ dos 6 pacientes normozoospérmicos. As médias dos resultados de $\mathrm{GH}$ dos testes realizados nos 3 grupos estudados estão contidos na tabela 1 . Os valores dos resultados dos 5 testes normais são apresentados na tabela 2 . Não foi observada diferença significativa nos valores de $\mathrm{GH}$ das respostas de 60,90 e 120 minutos após estímulo entre os grupos I, II e III e, também, entre os subgrupos IIIa e IIIb.

\section{DISCUSSĀO}

São muitas as evidências clínicas de que o GH e o IGF1 cstão envolvidos na espermatogênese $(2,5)$. No homem, a resposta testicular ao hormônio gonadotrófico coriônico é diminuída em pacientes com deficiên' cia ou resistência ao GH (8). Em homens com hipogonadismo hipogonadotrófico, a adição de $\mathrm{GH}$ ao tratamento com gonadotrofinas aumenta a produção 
Tabela 1. Valores de $\mathrm{GH}$ (médiatdesvio padrão, em $\mathrm{ng} / \mathrm{ml}$ ) no teste de estímulo pela clonidina nos 3 grupos estudados.

\begin{tabular}{|c|c|c|c|c|c|}
\hline GRUPO & $n$ & BASAL & APÓS 60' & APÓS 90' & APÓs 120' \\
\hline \multirow[t]{2}{*}{ GRUPO I } & 9 & 0,261 & 0,281 & 1,533 & 1.966 \\
\hline & & \pm 0.091 & $\pm 0,081$ & $\pm 0,510$ & $\pm 1,341$ \\
\hline \multirow[t]{2}{*}{ GRUPO II } & 9 & 0,518 & 0,468 & 1,849 & 1.117 \\
\hline & & $\pm 0,442$ & $\pm 0,122$ & $\pm 0,943$ & \pm 0.397 \\
\hline \multirow[t]{2}{*}{ GRUPO III } & 11 & 0,201 & 1,264 & 2,94 & 1,522 \\
\hline & & $\pm 0,151$ & $\pm 0,552$ & $\pm 0,784$ & $\pm 0,429$ \\
\hline \multirow[t]{2}{*}{ GRUPO IIIa } & 5 & 0,026 & 0,87 & 1,68 & 0,87 \\
\hline & & $\pm 0,007$ & $\pm 0,672$ & $\pm 0,376$ & $\pm 0,690$ \\
\hline \multirow[t]{2}{*}{ GRUPO IIIb } & 6 & 0,346 & 1,592 & 3,99 & 2,067 \\
\hline & & $\pm 0,271$ & $\pm 0,892$ & \pm 1279 & $\pm 0,433$ \\
\hline
\end{tabular}

Tabela 2. Valores dos resultados de $\mathrm{GH}(\mathrm{em} \mathrm{ng} / \mathrm{ml}$ ) no teste de clonidina-GH nos 5 pacientes com resultados normais.

\begin{tabular}{cccccc}
\hline PACIENTES & $\begin{array}{c}\text { DOSE DE CLONIDINA } \\
(\mathrm{mg})\end{array}$ & BASAL & APÓS 60' & APÓS 90' & APÓS 120' \\
\hline 1 & 0,150 & 0,5 & 0,6 & 6,9 & 12,6 \\
2 & 0,200 & 0,1 & 0,3 & 8,0 & 2,9 \\
3 & 0,400 & 1,7 & 5,2 & 7,2 & 2,8 \\
4 & 0,400 & 0,04 & 0,06 & 6,0 & 3,4 \\
5 & 0,400 & 0,06 & 3,3 & 6,7 & 3,9 \\
\hline
\end{tabular}

de testosterona e a concentração espermática (9). O IGF-l é encontrado nas células de Sertoli e, em menor quantidade, nos espermatócitos primários $(4,10)$, estando essa produção regulada, pelo menos em parte, pelas gonadotrofinas. Receptores de IGF-l têm sido encontrados nas células de Leydig, onde o IGH-1 controla e facilita a síntese androgênica (11). Camundongos com ruptura do gene do IGF-1 mostram insuficiência espermatogênica, mais com respeito a quantidade do que a uma parada em determinada fase da espermatogênese (12). Junto a uma série de outros fatores de crescimento, como os da família do transforming growth factor $\beta$, o GH e o IGF- 1 parecem ser, antes que uma necessidade absoluta, fatores facilitantes de uma espermatogênese normal (13).

Estes dados têm estimulado a realização de testes de estímulo de GH em pacientes inférteis, visando detectar alterações na sua liberação. As avaliações laboratoriais até agora realizadas incluem testes de estímulo pelo growth hormone-releasing hormone (GH$\mathrm{RH}$ ) (14), pela arginina (15) e pela clonidina (7). Estes testes mostraram tênues evidências de que no homem subfértil pode existir uma anormalidade de produção e/ou secreção de $\mathrm{GH}$, o que poderia ter implicações terapêtuticas $(2,5)$.

Segundo Shimonovitz e cols. (7), o teste de clonidina resultou negativo em $91 \%$ dos casos de azoospermia avaliados, ao passo que em $82 \%$ dos casos de oligozoospermia e em todos os pacientes férteis o mesmo teste mostrou resposta normal do GH ao estímulo. Estes dados nos animaram a passar a realizar esse mesmo teste em todo paciente infértil em que fosse ser realizado um teste de $\mathrm{LH}-\mathrm{RH}$, tendo sido este o único critério de escolha. A ausência de resposta na maioria dos pacientes nos fez, de início, supor que a causa estivesse relacionada a uma insuficiência da dose clássica de clonidina $(0,150 \mathrm{mg})$, pelo que elevamos a mesma para $0,200 \mathrm{mg}$, ainda em pacientes oligozoospérmicos, o que não alterou o padrão de resposta previamente obtido. A dose de clonidina foi, então, aumentada para $0,400 \mathrm{mg}$, e incluídos no estudo pacientes normozoospérmicos, o que resultou em um maior número de respostas normais nestes pacientes normozoospérmicos. No entanto, esta maior incidência de respostas normais não foi estatisticamente significativa, o que poderia ser atribuído à reduzida amostragem por nós estudada.

Afastada a possibilidade destes resultados se deverem a uma dose insuficiente de clonidina, as únicas explicações possíveis seriam, ou que a maioria destes pacientes têm realmente insuficiência relativa de $\mathrm{GH}$, ou que a clonidina não seria um estímulo adequado para este diagnóstico. A primeira hipótese seria afastada pelos achados de resposta de GH normal, ainda que com diferença significativa daquelas de homens normais, na totalidade dos inférteis submetidos à infusão de arginina (14) e de GH-RH (15). Resta a hipótese da clonidina ser ineficaz como agente estimulante do GH. 
A clonidina, um agonista central alfa-2-adrenérgico, é um poderoso estimulador do GH-RH na criança e no adolescente, sendo no adulto muito pouco específico e, na verdade, sem uso diagnóstico na insuficiência de GH do adulto (16). Rahim e col. (16), estudando 18 homens normais com idade média de 22 anos e usando doses de 0,100 a $0,200 \mathrm{mg}$ de clonidina, conclúram que a clonidina não é recomendada como um teste de avaliação do $\mathrm{GH}$, sendo seus efeitos comparáveis aos de um placebo. Acreditamos poder afirmar, por nossos achados, que mesmo uma dose de $0,400 \mathrm{mg}$ de clonidina é ineficaz como estimulante do GH.

Em que pese não termos incluído em nosso estudo um grupo controle de pacientes não inférteis, nossa conclusão é que o teste da clonidina, qualquer que seja a dose usada, não é de utilidade no diagnóstico de uma insuficiência relativa de GH no homem infértil, sendo a causa a inadequação da clonidina para estimular GH em homens adultos. Não sabemos como explicar os resultados e as conclusões do estudo de Shimonovitz e col. (7).

\section{REFERÊNCIAS}

1. Ovesen P, Moller J, Moller N, Christoansen JS, Oskov H, Jorgensen JOL. Growth hormone secretory capacity and insulin-like growth factor-l levels in primary infertile. anovulatory women with regular menses. Fertil Steril 1992; $57: 97-101$.

2. Shoham Z, Zalel Y, Jacobs HS. The role of growth hormone in male infertility. Clin Endocrinol (Oxf) 1994:41:1-5.

3. Ovesen $P$, Ingersley $H J$, Orskov $H$, Ledet $T$. Effect of growth hormone on steroidogenesis, insulin-like growth factor-I (IGF-I) and IGF-binding protein-I and DNA synthesis in cultured human luteinized granulosa cells. J Endocrinol 1994;140:313-9.

4. Saez JM. Leydig cells: endocrine, paracrine and aurocrine regulation. Endocr Rev 1994; 15:574-626.

5. Ovesen $\mathrm{P}$, Jorgensen JOL, Ingerslev J, Ho KKY, Orskov H, Christianses JS. Growth hormone treatment of subfertile males. Fertil Steril 1996;66:292-8.

6. Anaplotou MGL, Evagellou MD, Kastanias I, Liparaki M, Psara P. Goulandris N. Effect of growth hormone cotreatment with human chorionic gonadotropin in tes- ticular steroidogenesis and seminal insulin-like growth factor in oligozoospermia. Fertil Steril 1996;66:305-11.

7. Shimonovitz S, Zacut D, Bem Chetrit A, Ron M. Growth hormone status in pacients with maturation arrest of spermatogenesis. Human Reprod 1993;8:919-21.

8. Tato L, Zamboni G. Antoniazzi F, Piubello G. Gonadal function and response to growth hormone $(\mathrm{GH})$ in boys with isolated $\mathrm{GH}$ deficiency and to $\mathrm{GH}$ and gonadotropins in boys with multiple pituitary hormone deficiencies. Fertil Steril 1996;65:830-40.

9. Shoham Z, Conway GS, Ostergaard H, Lahlou N, Bouchard P, Jacobs HS. Cotreatment with growth hormone for induction of spermatogenesis in patients with hypogonadotropic hypogonadism. Fertil Steril 1992;57: 1044-51.

10. Vannelli BG, Barni T, Orlando C, Natali A, Serio M, Baldoni GC. Insulin-like growth factor-I (|GF-I) IGF-I receptor in human tests: na immunohistochemical study. Fertil Steril 1988;49:666-9.

11. Nagpal ML, Wang D, Calkins JH. Human chorionic gonadotropin up-regulates insulin-like growth factorreceptorgene expression of Leydig cells. Endocrinology $1991 ; 129: 2820-6$.

12. Baker J, Liu J, Robertson EJ, Efstratiadis A. Role of insulinlike growth factors in embryonic and postnatal growth. Cell 1993;75:73-82

13. Lamb DJ. Growth factors and testicular development. J Urol 1993; 150:583-92.

14. Rajmil O. Rodriguez-Espinosa J, Sarquella J, Castellet R, Oliver A, Queralto JM. Growth hormone response to growth hormone-releasing hormone stimulation in oligozoospermic pacients. Fertil Steril 1994:62:1039-43.

15. Ovesen P, Jorgensen JOL, Kjaer T, Ho KY, Orskov H, Christiansen JS. Impaired growth hormone secretion and increased growth hormone-binding protein levels in subfertile males. Fertil Steril 1996:65:165-9.

16. Rahim A, Toogood AA, Shalet SM. The assessment of growth hormone status in normal young adults using a variety of provocative agents. Clin Endocrinol (Oxford) 1996:45:557-62.

\section{Endereço para correspondência:}

Antônio Carlos Bonaccorsi

Av. N. Sra. Copacabana 647 sala 1115

22050-000 Rio de Janeiro, RJ.

Fax: (021)235-2240 